\title{
Resting heart rate and the effects of an incentive*
}

\author{
JAMES F. EVANS† \\ Lakehead University, Thunder Bay, Ont., Canada
}

One purpose of this study was to determine whether an incentive such as competition would cause increments in the performance of Ss with low resting heart rates and decrements in the performance of Ss with high resting heart rates. Another purpose of the study was to investigate further the hypothesis that an increase in incentive is accompanied by an increase in heart rate. The results supported the hypothesis that an increase in incentive is accompanied by an increase in heart rate and also indicated that the relationship between incentive and heart rate is not affected by resting heart rate level. No performance differences were found.

In a recent paper, Evans (1971) reported that rivalry, a cognitive desire to win, caused significant increases in tonic heart rate (heart rate measured over at least a $1 / 2$-min period) but did not affect concomitant performance on a form board. In accordance with recent work (Elliott, 1969; Elliott, Bankart, \& Light, 1970) indicating that an increase in tonic heart rate is indicative of an increase in incentive, Evans (1971) interpreted these results as indicating that rivalry is an incentive. The question of why the effects of an incentive were not reflected in performance was left open. One possible reason for this occurrence was that the presence of rivalry caused the performance of some Ss to improve while at the same time causing the performance of other Ss to deteriorate. These opposite effects of rivalry would tend to nullify one another, thereby preventing any overall effect of performance from emerging. One purpose of the present study was to determine if an incentive such as competition, i.e., both rivalry and coaction social facilitation, would cause increments in the performance of Ss with low resting heart rates and decrements in the performance of Ss with high resting heart rates. These results were predicted in accordance with the inverted- $U$ hypothesis which postulates that increased activation up to a certain point is beneficial to performance, but that beyond that point, increased activation is detrimental to performance (Duffy, 1962; Hebb, 1955; Malmo, 1959). Another purpose of the present study was to investigate further Elliott's

* This research was supported by Grant APA-306 from the National Research Council of Canada. A preliminary version of this paper was read at the Annual Meeting of the Canadian Psychological Association, June 1971.

tRequests for reprints should be sent to the author, Department of Psychology, Lakehead University, Thunder Bay, Ont., Canada.
(1969) hypothesis that an increase in incentive is accompanied by an increase in tonic heart rate.

$$
\text { METHOD }
$$

The Ss were 64 men and 64 women recruited from introductory and upper level psychology courses during a summer session.

The Ss sat at a table facing a wall. The tasks consisted of two identical form boards each with 24 pieces of different shapes and sizes. Each piece had a particular slot in the form board, and Ss could insert the pieces into the proper slot using their preferred hands. Heart rate was recorded, by means of a Gilson Model-M5P polygraph with a finger pick-up transducer, Model FP-6, from the index finger of the nonpreferred hand. The polygraph, and other experimental equipment when not in use, was out of sight behind a curtain.

Initially, the $\mathrm{E}$ brought a $\mathrm{S}$ into the experimental room, showed the polygraph to him, and explained that his heart rate (HR) would be recorded while he was performing a certain psychomotor task under various conditions. The $\mathrm{S}$ was then asked to sit down at the table, and the recording apparatus was attached and adjusted to obtain a satisfactory $\mathrm{HR}$ recording. Heart rate was recorded continuously from this point on. Instructions were given asking the $S$ to relax. After $3 \mathrm{~min}$ of relaxation, a form board was brought out and the $\mathrm{S}$ was familiarized with it by having two practice trials and $3 \mathrm{~min}$ to explore it. A trial was then performed which consisted of seeing how many blocks out of a total of 24 could be properly inserted into the form board within a 1-min period. These data comprised the basal performance data. Up to this point, all Ss were treated identically. Ss were then assigned randomly to a competitive or a noncompetitive condition. For Ss in the competitive condition, a confederate of the same sex as the $S$ was brought into the experimental room and another form board, identical to the S's, was brought out and set on the table beside the $S$. The confederate sat down in front of the form board, and instructions were read telling the $S$ and the confederate to try to do the task faster than the other person. Ss in the noncompetitive condition performed the second trial under conditions identical to the first. This procedure resulted in obtaining data on 33 males in the competitive condition, 36 males in the noncompetitive condition, 38 females in the competitive condition, and 38 females in the noncompetitive condition. Ss were then eliminated if they had been in a similar experiment before-one was rejected because his HR data were uninterpretable, and others were eliminated randomly until there were 32 males and 32 females in each of the competitive and noncompetitive conditions, resulting in a total of $128 \mathrm{Ss}$. Ss within each condition were then ranked from highest to lowest on the basis of their third minute of resting HR. This was done separately for males and females, since men are known to have lower HRs than women (Kimber, Gray, Stackpole, \& Leavell, 1961). The upper and lower quartiles, i.e., the 8 males and 8 females in each condition with the highest and lowest resting HRs were then designated as the high-HR and low-HR groups, respectively. This procedure resulted in a 2 by 2 factorial design with a total of 64 Ss. Competition and noncompetition comprised one factor, and high and low resting $\mathrm{HR}$ comprised the other factor. The four resultant groups, each consisting of 16 Ss, 8 males and 8 females, were: (1) competition/high-HR, (2) competition/low-HR, (3) noncompetition/high-HR, and (4) noncompetition/low-HR.

$$
\text { RESULTS }{ }^{1}
$$

A 2 by 2 factorial analysis of variance was performed on the resting $H R$ data and as expected, because the high-HR and low-HR conditions were formed on the basis of resting HR, there was a significant difference between the high-HR and low-HR conditions $(F=297.55, \quad \mathrm{df}=1 / 60$, $\mathrm{p}<.001)$. The mean resting $\mathrm{HR}$ for the high-HR conditions was 95.38 beats per minute (bpm), and for the low-HR conditions it was $63.88 \mathrm{bpm}$. The difference in resting heart rate between the competitive $(\overline{\mathrm{X}}=78.53 \mathrm{bpm})$ and noncompetitive $(\overline{\mathrm{X}}=80.72 \mathrm{bpm})$ conditions was not significant $(F=1.43, \mathrm{df}=1 / 60, \mathrm{n} . \mathrm{s}$.$) .$ There was no indication of an interaction.

The mean performance scores for the four groups and two trials are presented in Table 1 . A 2 by 2 by 2 factorial analysis of variance with the 


\begin{tabular}{|c|c|c|c|c|c|c|c|c|c|}
\hline & & Trial 1 & Trial 2 & $\begin{array}{l}\text { Change } \\
\text { Score }\end{array}$ & & & Trial 1 & Trial 2 & $\begin{array}{l}\text { Change } \\
\text { Score }\end{array}$ \\
\hline Competition & $\begin{array}{l}\text { High HR } \\
\text { Low HR }\end{array}$ & $\begin{array}{l}9.12 \\
9.81\end{array}$ & $\begin{array}{r}10.12 \\
9.50\end{array}$ & $\begin{array}{r}1.00 \\
-.31\end{array}$ & Competition & $\begin{array}{l}\text { High HR } \\
\text { Low HR }\end{array}$ & $\begin{array}{r}108.62 \\
79.06\end{array}$ & $\begin{array}{r}118.31 \\
88.88\end{array}$ & $\begin{array}{l}9.69 \\
9.82\end{array}$ \\
\hline $\begin{array}{l}\text { Noncompe- } \\
\text { tition }\end{array}$ & $\begin{array}{l}\text { High HR } \\
\text { Low HR }\end{array}$ & $\begin{array}{l}9.00 \\
9.50\end{array}$ & $\begin{array}{r}10.25 \\
9.94\end{array}$ & $\begin{array}{r}1.25 \\
.44\end{array}$ & $\begin{array}{l}\text { Noncompe- } \\
\text { tition }\end{array}$ & $\begin{array}{l}\text { High HR } \\
\text { Low HR }\end{array}$ & $\begin{array}{r}111.25 \\
79.25\end{array}$ & $\begin{array}{r}109.81 \\
81.88\end{array}$ & $\begin{array}{r}-1.44 \\
2.63\end{array}$ \\
\hline
\end{tabular}

repeated measures, Trials 1 and 2 , being the additional factor, was performed on the performance data. No between-group differences were significant. The general increase in performance from Trial 1 to Trial 2 was significant $(F=4.83, \mathrm{df}=1 / 60$, $\mathrm{p}<.05$ ), but there were no significant interactions with this increase.

The mean HR scores for the four groups and two trials are presented in Table 2. A 2 by 2 by 2 factorial analysis of variance was performed on the HR data. The only significant between-group difference was a significant difference between the high-HR and low-HR conditions $(F=103.60, \quad d f=1 / 60, \quad p<.001)$. This result was expected, since intra-S correlations between different HR scores are always very high and significant and the high-HR and low-HR conditions had been formed on the basis of resting $\mathrm{HR}$. The general increase in HR from Trial 1 to Trial 2 was significant $(\mathrm{F}=36.90, \mathrm{df}=1 / 60$, $\mathrm{p}<.001)$. Also, the Competition by Trials interaction was significant $(\mathrm{F}=28.88, \mathrm{df}=1 / 60, \mathrm{p}<.001)$; the data indicate that the competitive conditions were responsible for a greater increase in HR from Trial 1 to Trial 2 than were the noncompetitive conditions. The mean $\mathrm{HR}$ increase for the competitive conditions was 9.76 bpm, and for the noncompetitive conditions it was $.60 \mathrm{bpm}$. The other interactions were not significant.

\section{DISCUSSION}

If one thinks of the introduction of competition as an incentive, the present HR data provided further support for Elliott's (1969) hypothesis that an increase in incentive is accompanied by an increase in tonic HR. It is noteworthy that the introduction of competition caused an increase in HR of approximately $10 \mathrm{bpm}$ regardless of resting $\mathrm{HR}$ level. In other words, no evidence of a ceiling effect in regard to the relationship between incentive and $H R$ was found. No between-group performance differences were found, and accordingly there was no indication of the predicted inverted- $U$ relationship between resting $\mathrm{HR}$ and incremental or decremental performance in a competitive situation. The finding of an increase in incentive not being reflected in form board performance (Evans, 1971) was replicated. The question of why this phenomenon occurs has still not been answered and requires further investigation.

\section{REFERENCES}

DUFFY, E. Activation and behavior. New York: Wiley, 1962.

ELLIOTT, R. Tonic heart rate: Experiments on the effects of collative variables lead to a hypothesis about its motivational significance. Journal of Personality \& Social Psychology, 1969, 12, 211-228.

ELLIOTT, R., BANKART, B.. \& LIGHT, T, Differences in the motivational significance of heart rate and palmar conductance: Two tests of a hypothesis. Journal of Personality \& Social Psychology, 1970, 14, 166-172.

EVANS, J. F. Social facilitation in a competitive situation. Canadian Journal of Behavioural Science, 1971, 3, 276-281.

HEBB, D. O. Drives and the conceptual nervous system. Psychological Review, $1955,62,243-254$.

KIMBER, D. C., GRAY , C. E., STACKPOLE, C. E., \& LEAVELL, L. C. Anatomy and physiology. New York: Macmillan, 1961.

M ALMO, R. B. Activation: A neuropsychological dimension. Psychological Review, 1959, 66, 367-386. NOTE

1. All analyses reported were also done taking sex out as another factor. No information was obtained that would lead to any conclusions different from those drawn in the present paper. 